\title{
The knowledge of public access to defibrillation in selected cities in Poland
}

\author{
Dariusz Kozłowski ${ }^{1,2}$, Tomasz Kłosiewicz' ${ }^{2}$, Adam Kowalczyk ${ }^{1}$, Anna Krystyna Kowalczyk ${ }^{3}$, \\ Edward Koźluk4, Maria Dudziak ${ }^{5}$ Wojciech Homenda², Grzegorz Raczak ${ }^{1}$
}

1Department of Cardiology and Electrotherapy, Medical University of Gdansk, Poland ${ }^{2}$ Chair of Health Sciences, Pomeranian Academy, Slupsk, Poland

3Department of Public Health and Social Medicine, Medical University of Gdansk, Poland ${ }^{4} 1^{\text {st }}$ Chair and Department of Cardiology, Medical University of Warsaw, Poland

${ }^{5}$ Noninvasive Diagnostic Cardiovascular Department, Medical University of Gdansk, Poland

Submitted: 16 September 2011

Accepted: 21 September 2012

Arch Med Sci 2013; 9, 1: 27-33

DOI: $10.5114 /$ aoms.2013.33345

Copyright $\odot 2013$ Termedia \& Banach

\begin{abstract}
Introduction: The Public Access to Defibrillation (PAD) program was designed to raise the awareness of sudden cardiac death (SCA) pre-hospital management among the community. The goal of the following research was to confirm the final impact of the Polish PAD program on various resident groups that differ by age, training and education level.

Material and methods: The trial total number of participants reached 404 people from three cities divided into two groups. In group one $(n=295)$ were randomly selected people inside the trial area and in group two $(n=109)$ we had individuals who were theoretically trained in basic life support (BLS) algorithms, including the use of an automatic external defibrillator (AED). The research method was based on two different questionnaires completed by participants from each group.

Results: The greatest knowledge of SCA, as well as the use of AED, and the best practical skills, were possessed by the residents of cities with a population over 100 000, aged between 18 and 30 years, who completed secondary or higher education (31.7\%). The group with the smallest knowledge about SCA lived in the country (10.7\%). The second group with little knowledge of the subject consisted mostly of individuals with primary education (4.19\%) or professional abilities and over 50 years old (2.16\%).

Conclusions: There must be some actions taken in order to increase the community awareness concerning automatic defibrillation. Training on AED and the possibility of practical exercise needs to be organized and should be conducted especially among residents of the countryside and people under 30 or over 50 years old.
\end{abstract}

Key words: sudden cardiac death, automatic external defibrillator, ventricular fibrillation, resuscitation.

\section{Introduction}

Defibrillation is a medical procedure that delivers a direct current impulse of energy to the heart through the chest surface. The key point of the defibrillation mechanism is the total heart muscle depolarization. It causes orderliness of electric charges and brings back the regular conduction in the heart conduction system usually in order to terminate lifethreatening tachycardias.

\author{
Corresponding author: \\ Prof. Dariusz Kozłowski \\ Department of Cardiology \\ and Electrotherapy \\ Medical University of Gdansk \\ 7 Debinki Str. \\ 80-211 Gdansk, Poland \\ Phone: +48583493910 \\ Fax: +48 583493920 \\ E-mail: dkoz@gumed.edu.pl
}


In 1990 the American Heart Association (AHA) first defined the "chain of survival" as a sequence of actions needed to be done in case of cardiac arrest [1]. Nowadays, this chain is an international standard in rescue medicine. The "chain of survival" consists of four components: early access to help (emergency call), early cardiopulmonary resuscitation (CPR), early defibrillation and early advanced care (Advanced Cardiovascular Life Support - ACLS) [2].

Defibrillation, according to the newest guidelines of the AHA and European Resuscitation Council (ERC), is the most important component of the "chain of survival" and significantly improves the survival rate after sudden cardiac arrest in the ventricular fibrillation (VF) mechanism [3, 4].

The PAD program was introduced in Poland in 2000 and has been well known for years within the rescue communities around the world [5]. Different types of rescue associations aim to spread the knowledge to the youth, the disabled, and drivers. The PAD program's goal is to place an automated external defibrillator (AED) where at least one of these three situations occur: a sudden cardiac arrest happened at least once in the last 2 years, there is no possibility for a rescue team to arrive within $5 \mathrm{~min}$, and the AED can be delivered to the patient in less than 5 min [6].

A significant increase in the survival rate was observed within the group of lethal arrhythmia victims in countries where the PAD program was implemented effectively [7]. In other cases, the patient's chance of survival depends on the speed and quality of basic life support (BLS) performed by a witness [8]. The time from the moment of cardiac arrest to the first defibrillation procedure is also crucial for the patient's chance of survival [9].

The purpose of this research was to verify the program's premises in practice and to raise the awareness of the AED handling aspect [10]. The research covered Szczecin, Poznan and Slupsk. A closed-question questionnaire was used to determine the knowledge of the subject. The participants

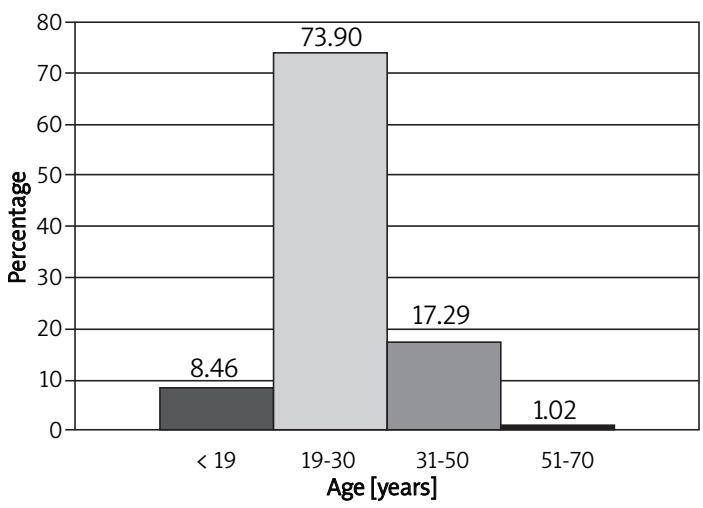

Figure 1. Age of the questioned were divided into two groups. The first group included randomly selected people within the trial area. The second group included people properly trained in basic life support methods and the use of an automatic defibrillator (BLS-AED). The questionnaires for these two groups differed from each other in the difficulty of the questions [11].

\section{Material and methods}

Total participants included 404 people: 203 women (50.25\%) and 201 men (49.75\%). There was no age limit for participants; the average age was 19-30 years. $73.90 \%$ of the participants were $19-30$ years old. These people were the most eager to complete the questionnaire and the trial itself $17.29 \%$ of the participants were $31-50$ years old and $8.46 \%$ under 19 years old. The smallest group (1.02\%) included participants 51-70 years old. There were no participants over 70 years old (Figure 1 ).

The trials were conducted in public facilities supplied with AED. The interviewees were divided into two groups: group one, 295 randomly selected people inside the trial area; and group two, 109 people trained in basic life support methods, such as the use of an automatic defibrillator (BLS-AED). There were 16 closed-ended questions for the first group (Table I) and 18 questions for the second one (Table II). The questionnaires for these two groups differ from each other in the content. In spite of the low access to AED in Poland, the places of interview were not intentionally specified. The trial was conducted from 1.02.2010 to 30.04.2010 in Poznan, Szczecin and slupsk.

\section{Results}

\section{Knowledge concerning sudden cardiac arrest}

The interviewees from the first group were questioned on their knowledge concerning SCA. $65.71 \%$ of the respondents answered correctly. Among this group $64.88 \%$ were men, $35.12 \%$ were women, $52.88 \%$ had secondary education, $39.79 \%$ a higher education, $4.19 \%$ primary education and $3.19 \%$ professional abilities. The level of participants' knowledge increased with the size of the city. In a city with over 100000 citizens the correct answer was given by $55.61 \%$ of respondents, $17.79 \%$ in a city of 20000 to 100000 residents, $13.90 \%$ in a town with less than 20000 residents and by $10.70 \%$ of those who live in the country. The highest number of correct answers was given by the interviewees in the age group $19-30$ years old (73.38\%), then those 31 50 years old (18.71\%), followed by the group under 19 years old (5.76\%). The lowest level of knowledge was among people $51-70$ years old (2.16\%). $74.39 \%$ of respondents knew that SCA is a direct life-threat- 
Table I. Questionnaire for customers (1st group)

\begin{tabular}{|c|c|}
\hline \multicolumn{2}{|c|}{$\begin{array}{l}\text { This is a questionnaire concerning the use of an automatic defibrillator (AED). The results of this questionnaire will be } \\
\text { used for my Bachelor's degree thesis. This questionnaire is completely anonymous. There are no "good" or "bad" answers. } \\
\text { Choose the answer you agree the most with. Please check only one answer. Thank you for filling in this questionnaire. }\end{array}$} \\
\hline $\begin{array}{l}\text { 1. Do you know what sudden cardiac arrest (SCA) means? } \\
\text { a) Yes. } \\
\text { b) No. }\end{array}$ & \multirow{2}{*}{$\begin{array}{l}\text { 10. Would you use the AED, knowing about its accessibility, } \\
\text { in the situation of sudden cardiac arrest? } \\
\text { a) Yes. } \\
\text { b) No. } \\
\text { c) I do not know. }\end{array}$} \\
\hline $\begin{array}{l}\text { 2. Do you know that SCA is a direct life-threatening } \\
\text { condition? }\end{array}$ & \\
\hline $\begin{array}{l}\text { a) Yes. } \\
\text { b) No. }\end{array}$ & \multirow{2}{*}{$\begin{array}{l}\text { 11. If not, please state why: } \\
\text { a) I don't remember how to use it, } \\
\text { b) I don't know how to use it, } \\
\text { c) I am afraid of using it incorrectly, } \\
\text { d) I am afraid of the consequences, }\end{array}$} \\
\hline $\begin{array}{l}\text { 3. Do you know what an automatic external defibrillator } \\
\text { (AED) is? }\end{array}$ & \\
\hline $\begin{array}{l}\text { a) Yes. } \\
\text { b) No. }\end{array}$ & \multirow{2}{*}{$\begin{array}{l}\text { 12. Please state your gender: } \\
\text { a) female, } \\
\text { b) male. }\end{array}$} \\
\hline $\begin{array}{l}\text { 4. Do you know that it is placed in the facility that you are } \\
\text { now in? }\end{array}$ & \\
\hline $\begin{array}{l}\text { a) Yes. } \\
\text { b) No. }\end{array}$ & \multirow{2}{*}{$\begin{array}{l}\text { 13. Please define your level of education: } \\
\text { a) primary, } \\
\text { b) professional abilities, } \\
\text { c) secondary, } \\
\text { d) higher. }\end{array}$} \\
\hline $\begin{array}{l}\text { 5. Do you know where you should look for it? } \\
\text { a) Yes. } \\
\text { b) No. }\end{array}$ & \\
\hline $\begin{array}{l}\text { 6. Have you ever completed first aid training? } \\
\text { a) Yes. } \\
\text { b) No. }\end{array}$ & $\begin{array}{l}\text { 14. Please define your type of education: } \\
\text { a) medical degree, } \\
\text { b) paramedical degree (paramedic, nurse), } \\
\text { c) non-medical. }\end{array}$ \\
\hline $\begin{array}{l}\text { 7. If yes, please define when: } \\
\text { a) before the year } 2000 \text {, } \\
\text { b) years } 2001-2005 \\
\text { c) after the year } 2006 \text {. }\end{array}$ & \multirow{2}{*}{$\begin{array}{l}\text { 15. Please define your place of living: } \\
\text { a) in the country, } \\
\text { b) town }<2000 \text { inhabitants, } \\
\text { c) city } 20000-100000 \text { citizens, } \\
\text { d) city }>100000 \text { citizens. }\end{array}$} \\
\hline 8. Do you know in which conditions the AED should be & \\
\hline $\begin{array}{l}\text { used? } \\
\text { a) Yes. } \\
\text { b) No. }\end{array}$ & \multirow{2}{*}{$\begin{array}{l}\text { 16. Please state your age: } \\
\text { a) < } 18 \text { years old, } \\
\text { b) } 19-30 \text { years old, } \\
\text { c) } 31-50 \text { years old, } \\
\text { d) } 51-70 \text { years old, } \\
\text { e) }>71 \text { years old. }\end{array}$} \\
\hline $\begin{array}{l}\text { 9. Do you know how to use the AED? } \\
\text { a) Yes. } \\
\text { b) No. }\end{array}$ & \\
\hline
\end{tabular}

ening condition. $57.59 \%$ of this group were men, $42.41 \%$ women.

\section{General knowledge concerning automatic external defibrillators}

$31.71 \%$ of respondents in the first group knew what an automatic external defibrillator was. Among them $71.38 \%$ were people in the age group $19-30$ years old, $18.17 \%$ were $31-50$ years old, $5.76 \%$ were under 19 years old and $2.16 \%$ were between 51 and 70 years old. The knowledge of AED increased with the size of the city. More than half of those questioned who possessed the knowledge lived in a city with over 100000 citizens, $19.79 \%$ in a city with a population of $2000-100000,13.90 \%$ in a town with less than 2000 residents and $10.70 \%$ lived in the country. There was a major positive cor- relation between the knowledge of the subject and education. $52.88 \%$ of interviewees had completed secondary education, $39.79 \%$ higher education, $4.19 \%$ primary education and $3.14 \%$ possessed professional abilities. The highest level of knowledge was among the participants within the group 1930 years old, with secondary education, living in cities with more than 100000 residents (Figure 2).

The device was accessible to the participants during the trial but only $5.28 \%$ of those questioned knew what an AED looked like and where it could possibly be located. Fifty-six percent of participants had completed first aid training, but only $41.88 \%$ knew what an AED was. Forty-two percent of these people were trained in 2006 and 2007, 24\% between 2000 and 2005, and 34\% before 2000, when knowledge of automatic defibrillation was not widespread. The defense training class in high school does not 
Table II. Questionnaire for employees (2nd group)

This is a questionnaire concerning the use of an automatic defibrillator (AED). The results of this questionnaire will be used for my Bachelor's degree thesis. This questionnaire is completely anonymous. There are no "good" or "bad" answers. Choose the answer you agree the most with. Please check only one answer. Thank you for filling out this questionnaire.

1. Do you know what sudden cardiac arrest (SCA) means?

a) Yes.

b) No.

2. Do you know that SCA is a direct life-threatening condition?

a) Yes.

b) No.

3. Are you informed, as an employee, about the presence of an automatic defibrillator (AED) at your work?

a) Yes.

b) No.

4. Do you know where it is located?

a) Yes.

b) No.

5. How long have you been working here?

a) $<1$ year.

b) 1-3 years.

c) 3-5 years.

d) $>5$ years.

6. Has there been any training concerning AED organized during this time?

a) Yes.

b) No.

7. Please specify when.

a) $<1$ year ago.

b) 1-3 years ago.

c) 3-5 years ago.

d) $>5$ years ago.

8. Did you take part in it?

a) Yes.

b) No.

9. If not, what was the reason?

a) Lack of access.

b) Insufficient funds.

c) Lack of time.

10. Do you know in which conditions the AED should be used?

a) Yes.

b) No.

provide any kind of knowledge about automatic defibrillation.

In comparison, $83.49 \%$ of respondents in the second group who worked in the trial facilities knew exactly where an AED could be located. Within that group most people (73.33\%) had worked there for more than 5 years, $1.22 \%$ more than a year, $7.78 \%$ between three and 5 years, and $6.67 \%$ between 1 and 3 years (Figure 3 ). Despite the training provided by the employer about the AED, there was no positive correlation between the level of knowledge and who completed the course.
11. Do you know how to use an AED?

a) Yes.

b) No.

12. Would you use an AED, being aware of its accessibility, in the situation of sudden cardiac arrest?

a) Yes.

b) No.

c) I do not know.

13. If not, please give the reason:

a) I don't remember how to use it,

b) I don't know how to use it,

c) I am afraid of using it incorrectly,

d) I am afraid of the consequences.

14. Please state your gender:

a) female,

b) male.

15. Please define your level of education:
a) primary,
b) professional abilities,
c) secondary,
d) higher.

16. Please define your type of education:

a) medical degree,

b) paramedical degree (paramedic, nurse),

c) non-medical.

17. Please define your place of living:

a) in the country,

b) town < 2000 inhabitants,

c) city $20000-100000$ citizens,

d) city > 100000 citizens.

18. Please state your age:

a) $<19$ years old,

b) 19-30 years old,

c) 31-50 years old,

d) 51-70 years old

e) $>70$ years old.
Knowledge of the circumstances and clinical conditions of automated external defibrillator usage

$22.76 \%$ of participants within the first group correctly answered the question "Do you know under what circumstances an AED should be used?". Among them $13.56 \%$ knew where they should look for it. The largest number of correct answers was given by people who graduated from high school (50\%) and had higher education (40\%). Only $13 \%$ of correct answers were given by people who grad- 


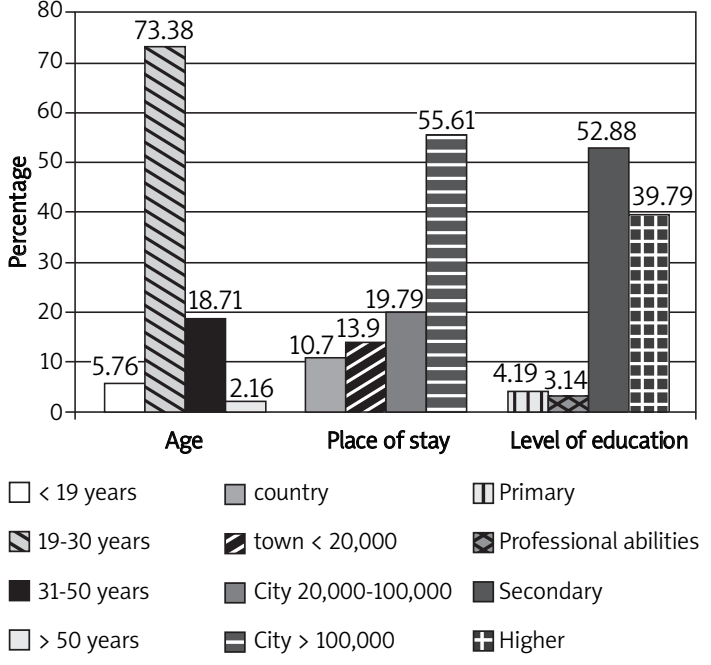

Figure 2. Knowledge of the what the AED is according to the age, place of stay and the level of education of the questioned

uated from primary school or possessed professional skills.

Sixty percent of these people were $19-30$ years old, $24 \% 31-50$ years old, $12 \%$ less than 19 years old and $4 \%$ were aged $51-70$ years.

There was a positive correlation between the level of knowledge and the size of the city where the participants live. $60.34 \%$ of the trial participants who had any knowledge of AED lived in a city with a population over 100 000, 17.24\% in a city with $20000-100000$ residents, $13.79 \%$ lived in the country and $8.62 \%$ lived in a town with a population less than $20000.32 .48 \%$ of those questioned who had knowledge on how to use an AED had completed a first aid course: $36.84 \%$ before $2000,41.67 \%$ in 2006 or later and $24.24 \%$ between 2000 and 2005 (Figure 4).

In comparison $78.90 \%$ of the questioned employees (second group) answered correctly about the circumstances under which an AED should be used. $33.72 \%$ of them had completed AED training.

\section{Use of automated external defibrillator in case of sudden circulatory arrest}

For a rescuer, an eyewitness, a SCA is undoubtedly a stressful situation. Knowing that any attempt to resuscitate may save the victim is the deciding factor for most eyewitnesses. An automatic external defibrillator highly facilitates resuscitation and is able to give directions regarding what steps should be taken. The AED helps to resuscitate according to an approved algorithm so it has a proven efficacy. In the condition of SCA not everybody among trial participants would have decided to use the AED (Figure 5). Only $25.44 \%$ of those questioned would do this $(65.79 \%$ of men and

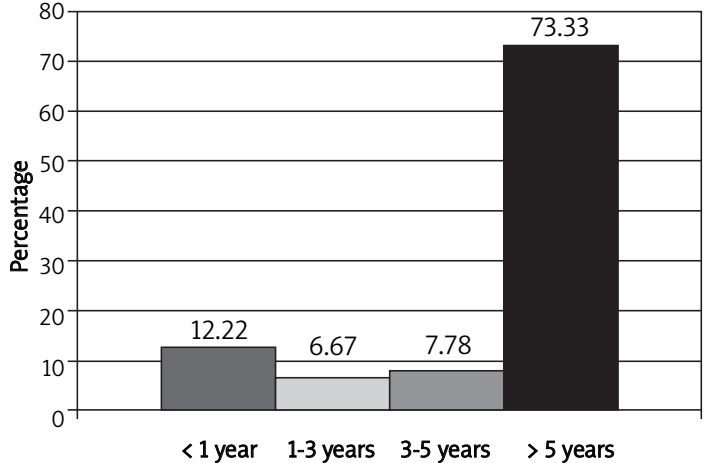

Figure 3. Job seniority of questioned employees who possess knowledge of AED presence at the work place

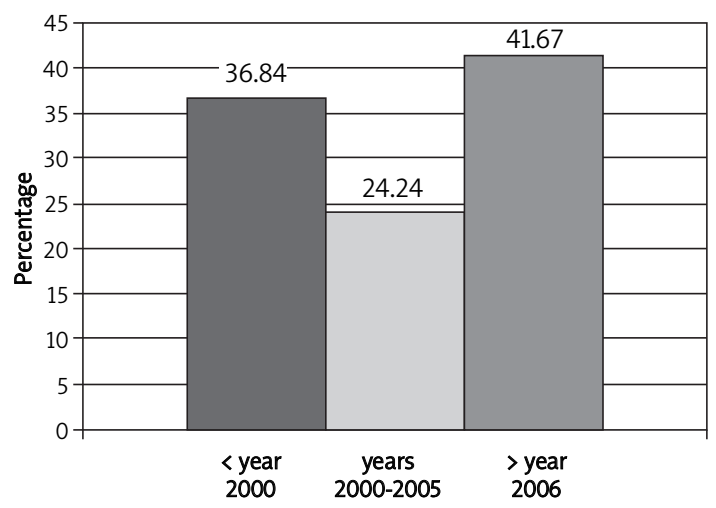

Figure 4. Knowledge of the circumstances in which the AED should be used according to the date of the first aid course graduation

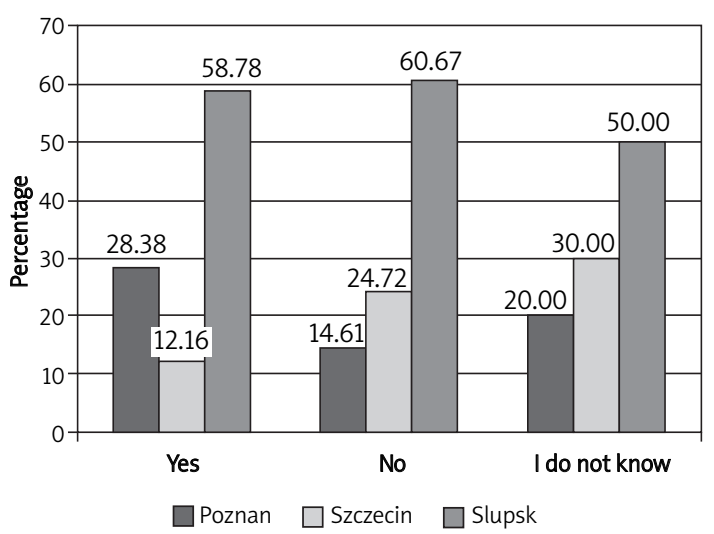

Figure 5. Results of the answers to the question: "Would you use the AED, knowing of its accessibility, in the situation of SCA?"

$34.21 \%$ of women). The largest group had higher education (58.62\%), then secondary education (36.21\%), professional abilities (3.45\%) and primary education (1.72\%). 63.64\% lived in a city with more than 100000 residents, $18.18 \%$ in a town with a population of less than 20000 residents, $12.73 \%$ in the country and $5.45 \%$ in a city with 20000 100000 residents. 
Young people (age 19-31 years) tend to have the best knowledge on how to use an AED. They made up $66.67 \%$ of the participants, $25 \%$ were $31-50$ years old, $5 \%$ were younger than 18 years old and $3.33 \%$ were between 51 and 70 years old.

$57.84 \%$ of those questioned could not decide if they would use the defibrillator under the circumstances of a SCA ( $55.5 \%$ women, $44.5 \%$ men). The greatest doubts were among the age group 19-30 years old (68.24\%), residents of a city with a population over 100000 (51.35\%) and those who had completed higher education (49.66\%).

The AED would not be used by $16.38 \%$ of those questioned ( $61.40 \%$ women, $38.60 \%$ men), $82 \%$ of people between 19 and 30 years old, $12 \%$ of those $31-50$ years old and $6 \%$ less than 19 years old. Fortyeight percent of them come from a city with a population exceeding 100 000, 30\% from a city with a population between 20000 and 100 000, 16\% from a town and $6 \%$ from the country. Sixty-two percent have completed secondary education, $28 \%$ higher education, $6 \%$ primary education or have personal abilities. Interviewees who were asked why they would not use the defibrillator answered accordingly: they did not know how to use it $(40.20 \%)$, they were afraid of using it incorrectly (24.66\%), they were afraid of the consequences of using it $(2.70 \%)$ or they did not remember how to use the device (1.68\%).

Among those who completed the first aid course $35.04 \%$ would employ the automatic defibrillator during the resuscitation. Half of this group was trained in 2000 or earlier, $31.82 \%$ between 2000 and 2006 and $16.67 \%$ in 2006 or later. $15.79 \%$ of those questioned who would use an AED knew how to use it, $7.89 \%$ knew its possible location and $19.47 \%$ knew exactly where it was.

The Public Access to Defibrillation program is not conducted effectively. Action must be taken in order to increase communities' awareness concerning automatic defibrillation. Training about the AED and practical exercises have to be organized and they should cover especially the residents of the countryside, people under 30 years old and students of primary, junior high and high schools. There should be additional classes to refresh the knowledge and skills for those who have completed the training previously. The proper marking of disposed defibrillators is essential.

\section{Discussion}

The Access to Defibrillation program has been ongoing in Poland for a few years. Despite the fact that SCA happens mostly outside of the hospital, still very few people can effectively give first aid when needed. Better and more adequate training that covers a large part of the community would be helpful. In general, people do not realize how impor- tant is the time elapsed between the SCA occurrence (during VF) and first defibrillation [12]. The training equipment is expensive and not always available $[13,14]$. Commercial campaigns and scientific programs on public television could improve the community awareness [15].

The greatest knowledge of SCA, as well as of AED, and the best practical skills were among residents aged between 18 and 30 years who had completed secondary or higher education in cities with a population over 100 000. The better results may be due to the fact that in this age group many people have completed the first aid course on their own initiative or as members of the community and rescue organizations. The participants expressed their interest in extending their skills regarding first aid procedures. There was a common opinion that such training should be organized as part of obligatory classes during education at different levels (primary, secondary and higher). Based on the research one may draw the conclusion that along with the size of the investigated city there was an increase of participants' knowledge level regarding the AED device: more than half of those questioned who possessed that knowledge lived in a city with over 100000 citizens, 19.79\% in a city with a population of $2000-100000,13.90 \%$ in a town with less than 2000 residents and $10.70 \%$ lived in the country. This situation may be a result of the general health awareness correlation that is present in some populations. Nevertheless, this finding needs further investigation and evaluation.

The group with the smallest knowledge about SCA included people living mostly in the country. Barely any kind of training is provided to them or the rescue teams covering those remote areas, and these teams are very rarely equipped with defibrillators. Death occurring as a result of not being able to give first aid during the first few minutes after SCA is very common in those areas. That is why the introduction of a "First Responder" unit equipped with an automatic defibrillator would be a good solution. Simultaneously, people should be educated about the basic life support techniques and defibrillator use. It seems to be necessary to introduce obligatory classes for students in primary and secondary schools in the country. Such training should be carried out by appropriately qualified staff and must be free of charge. Otherwise it will be treated as, yet another, redundant expense.

In spite of the difficulty of the topic, adequately qualified staff are needed to interpret the rules and algorithms in an easy and understandable way $[16,17]$. The most effective methods of teaching first aid for children and adults are simulations of real incidents, because in this way the trainee learns how to practically use previously gained theoretical knowledge $[18,19]$. A cheaper method, involving a film presenting the action and handling of the 
defibrillator, is available; however, this method is far less effective. Introducing these practical classes, especially in remote areas, could be well appreciated and accepted.

Only a small interest in the subject of SCA and its management is observed among interviewees aged above 50 years. This group is at higher risk of SCA because of age and other, mostly cardiological, illnesses, which may cause haemodynamic failure. Despite this fact, a low percentage of respondents (4.39\%) knew that there was a defibrillator in the trial facility, and only a little more (10.14\%) knew where it could be found.

There were only two trial places where the AED was properly marked with graphic symbols which could be seen from a distance; however, the device was not near the potential rescuer. Only in one case could the participant open the box and take out the defibrillator without engaging other people. In all other trial places only the staff members were authorized to use the AED. Some people simply did not know what the AED symbol was.

The research shows that people who had completed a first aid course had larger and deeper knowledge. These who completed the training in 2006 or later proved to have better theoretical knowledge about the AED. However, when further practical knowledge was tested, fewer correct answers were given. Around 2000 defibrillation was not the most common topic discussed in Polish medical society. The percentage of those who possessed theoretical knowledge increased along with the date of training.

\section{References}

1. Emergency Cardiac Care Guidelines. Part 12: "From science to survival: strengthening the chain of survival in every community". Circulation 2000; 102: I-358-70.

2. American Heart Association (AHA). 2008. AED programs q \& a.

3. Electrotherapy: automatic external defibrillators, defibrillation, cardioversion and electrostymulation. ERC Guidelines 2010

4. Maziar Zafari A, Zarter SK, Heggen V, et al. A program encouraging early defibrillation results in improved inhospital resuscitation efficacy. J Am Coll Cardiol 2004; 44: 846-52.

5. Weisfeldt ML, Kerber RE, McGoldrick RP, et al. Public access defibrillation, a statement for healthcare Professionals from the American Heart Association task force on automatic external defibrillation. Circulation 1995; 92 2763.

6. Culley LL, Rea TD, Murray JA, et al. Public access defibrillation in out-of-hospital cardiac arrest: a communitybased study. Circulation 2004; 109: 1859-63.

7. Caffrey SL, Willoughby PJ, Pepe PE, Becker LB. Public use of automated external defibrillators. N Engl J Med 2002; 347: 1242-7.

8. Kerber RE, Becker LB, Bourland JD, et al. Automatic external defibrillators for public access defibrillation. Circulation 1997; 95: 1677-82
9. Hallstrom A, Ornato J. Public-access-defibrillation and survival after out-of-hospital cardiac arrest. N Engl J Med 2004; 351: 637-46.

10. Larkin M. Should your facility have an AED? Make your community benefit really benefit. Health Care Strateg Manage 2007; 25: 1-3.

11. Groh WJ, Birnbaum A, Barry A, Anton A, Mann NC, Peberdy MA; PAD Trial Investigators. Characteristics of volunteers responding to emergencies in the Public Access Defibrillation Trial. Resustitation 2007; 72: 193-9.

12. De Maio V, Stiell I, Wells G, Martin MT, Doherty J, Spaite DW; the Ontario Pre-Hospital Advanced Life Support Group (OPALS). Potential impact of public access defibrillation based upon cardiac arrest location. Acad Emerg Med 2001; 8: 415-6.

13. Brown J, Kellerman AL. The shocking truth about automated external defibrillators. JAMA 2000; 284: 1438-41.

14. Rho RW, Page RL. The automated external defibrillator. J Cardiovasc Electrophysiol 2007; 18: 896-9.

15. Balady GJ, Chaitman B, Foster C, Froelicher E, Gordon N, Van Campal S. Automated external defibrillators in health/fitness facilities: supplement to the AHA/ACSM recommendations for cardiovascular screening, staffing, and emergency policies at health/fitness facilities. Circulation 2002; 105: 1147-50.

16. Meischke HW, Eisenberg MS, Schaeffer MA, Kudenchak P. Training seniors in the operation of an automated external defibrillator: a randomized trial comparing two training methods. Ann Emerg Med 2001; 38: 216-22.

17. Handley AJ, Handley SA. Improving CPR performance using an audible feedback system suitable for incorporation into an automated external defibrillator. Resuscitation 2003; 57: 57-62.

18. Page RL, Joglar JA, Kowal RC, et al. Use of automated external defibr illators by a U.S. air line. N Engl J Med 2000; 343: 1210-6.

19. Valenzuela TD, Roe DJ, Nichol G, Clark LL, Spaite DW, Hardman RG. Outcomes of rapid defibrillation by security officers after cardiac arrest in casinos. N Engl J Med 2000; 343: 1206-9. 